Research Article

\title{
Occupational Health and Safety Risk Assessment of Cruise Ship Construction Based on Improved Intuitionistic Fuzzy TOPSIS Decision Model
}

\author{
Xiang Ziquan (D), Yang Jiaqi, Muhammad Hamza Naseem $(D$, and Xiang Zuquan \\ School of Transportation and Logistics Engineering, Wuhan University of Technology, Wuhan 430063, China \\ Correspondence should be addressed to Xiang Ziquan; 402053662@qq.com
}

Received 19 June 2021; Revised 30 July 2021; Accepted 18 August 2021; Published 29 August 2021

Academic Editor: Harish Garg

Copyright (c) 2021 Xiang Ziquan et al. This is an open access article distributed under the Creative Commons Attribution License, which permits unrestricted use, distribution, and reproduction in any medium, provided the original work is properly cited.

\begin{abstract}
The logistics of cruise ship construction are complex, with an extended period, many participants, and a stringent node control. The resulting occupational health and safety risks have more risks and uncertainties. If it is not identified and controlled, it will lead to low efficiency of logistics management in the construction stage, leading to chain breaking and going out of control. In response to this situation, this article proposes an improved intuitionistic fuzzy TOPSIS decision model to evaluate occupational health and safety risks in cruise ship construction. First, based on field research and interviews, risk sources and risk evaluation criteria are determined, and experts are given different weights based on the relative importance of decision-making experts. Then, to reduce the ambiguity and uncertainty of the risk source information, the intuitionistic fuzzy weighted arithmetic average operator is used to aggregate the judicial opinions of experts to obtain the intuitionistic fuzzy aggregate decision risk matrix. To improve the accuracy of risk assessment results, subjective weight and objective weight are comprehensively considered. The stepwise weight assessment ratio analysis (SWARA) method is used to determine the subjective weight of the evaluation criteria, and the normal distribution method is used to determine the objective weight of the evaluation criteria. According to the relative closeness coefficient of each risk source to the positive-ideal solution, the ranking of the risk sources is obtained. Finally, taking a cruise ship construction as an example, the risk sources of occupational health and safety are sorted, sensitivity analysis is carried out and compared with other methods, and the targeted risk control measures are put forward, which verifies the effectiveness and correctness of the improved intuitionistic fuzzy TOPSIS decision model.
\end{abstract}

\section{Introduction}

Occupational health and safety risks can be defined as a combination of the possibility of safety production accidents and health damage. Occupational health and safety risk assessment determines the possibility of safety production accidents and health damage events. These are the prerequisites for the implementation of the occupational health and safety management and help to reduce or eliminate hazardous factors in production activities and the environment [1]. Occupational health and safety risk assessment can be defined as the process of analyzing, evaluating, and grading occupational health and safety risks caused by hazards, considering the adequacy of existing control measures and determining whether the risk is acceptable [2].
At present, fewer industries are using occupational health and safety management concepts, mainly in petroleum and construction companies, while fewer are used in China's shipbuilding or cruise ship construction companies. Tackling the independent design and construction of China's large cruise ships is an inherent demand for the country's shipbuilding industry to transform from traditional manufacturing to high-end equipment manufacturing. Cruise ship construction projects must control the quality of the project, deliver on time, and ensure the safe and stable progress of the construction process, which is facing enormous challenges and pressures.

Cruise ship construction projects involve many criteria such as wide fields, high difficulties, long time, poor environment, and many construction personnel, resulting in a 
high risk coefficient of occupational health and safety. In the construction process, cruise ships have the characteristics of single solid ship customization, complex logistics distribution levels, multispecialty and multiregional coordination, difficulty in controlling the entire production process, and heavy workload. Compared with ordinary ships, they have great design concepts, construction techniques, project management, control, and so on. Therefore, the risk assessment of occupational health and safety is critical because it directly affects shipbuilding enterprises' cost, quality, and social responsibility. Mitsubishi Heavy Industries of Japan underestimated the difference between luxury cruise ships and ordinary ships. They did not pay enough attention to occupational health and safety risks, and its losses have reached 2.4 billion US dollars. During the construction of the "Diamond Princess" cruise ship by Mitsubishi Shipyard in Japan in 2001, the fire affected most of the ship's hull due to accidental welding by the employees, which delayed delivery by five months and led to loss of 50 billion yen. During the construction of the "AIDA Prima" cruise ship, there were three successive fires due to the fire in the wires. The delivery period was forced to be severely postponed, and the loss reached US $\$ 2$ billion. In the global shipbuilding industry, Japan has rich experience in shipbuilding and is in a leading position. There have been many incidents of outof-control risks. It has sounded the alarm for Chinese shipbuilding companies. Therefore, assessing the occupational health and safety risks of cruise ship construction has important practical significance for constructing the country's first cruise ship. First, the natural environment; society; man-made technology, equipment, and materials; and other risk factors faced by the cruise project are to be analyzed and mastered. Through the risk assessment, the probability of accidents during cruise ship construction can be reduced and personnel safety and health can be guaranteed. Second, the occupational health and safety risks of cruise ship construction should be studied so that decisionmakers have a deep understanding of potential risks and put forward countermeasures to ensure the quality of the project and the punctual construction period to achieve the completion of the cruise ship construction on time. The occupational health and safety risk assessment of cruise ship construction can be regarded as an uncertain fuzzy multicriteria decision-making problem. Because of the highly uncertain and ambiguous characteristics of cruise ship construction, this paper proposes intuitionistic fuzzy numbers (IFNs) to describe the ambiguity and uncertainty. Zadeh [3] first proposed the fuzzy set theory to analyze the problem of fuzziness, but only a single scale (i.e., degree of membership) was used to define the fuzzy sets. It was based on the dichotomy and could not express the neutral state (neither support nor opposition). To further fully describe the ambiguity problem, Atanassov [4] proposed the intuitionistic fuzzy set theory in which two scales are used (namely, degree of membership and degree of nonmembership) to describe fuzziness and can simultaneously explain three states: affirmative, negative, and neutral, so the natural attributes of objective phenomena are described more delicately and more comprehensively. Hwang CL with Yoon K, in 1981, first proposed the technique for order preference by similarity to ideal solution (TOPSIS) method, usually also called the ideal point method. Since then, domestic and foreign scholars have done a lot of research work on applying the TOPSIS method in multiattribute decisionmaking, and it is widely used in investment decisionmaking, program selection, utility evaluation, and comprehensive evaluation [5-9]. Recently, many researchers have extended the TOPSIS method to solve the intuitionistic fuzzy multicriteria decision-making (MCDM) problem. Based on this, because of the uncertainty and complex ambiguity of the cruise ship construction occupational health and safety risk assessment, this article discusses the cruise ship construction occupational health and safety risk assessment from the perspective of intuitionistic fuzzy sets, adding subjective and objective weights to the assessment criteria, and proposes an improved intuitionistic fuzzy TOPSIS decision model. The improved intuitionistic fuzzy TOPSIS decision model uses a new MCDM (multicriteria decision-making) method, namely, the stepwise weight assessment ratio analysis (SWARA) method, to determine the subjective weight of the evaluation criteria and uses a normal distribution method to determine the objective weight of the evaluation criteria. The intuitionistic fuzzy weighted arithmetic average operator is used to aggregate the judicial opinions of experts, comprehensively consider various uncertainties, and comprehensively evaluate the subjective and objective weights of the evaluation criteria. The main contributions of this article are as follows:

(1) To fully consider the possibility of decision-makers' hesitation, intuitionistic fuzzy numbers are used to characterize the great uncertainty and ambiguity of occupational health and safety risks in cruise ship construction. Based on actual investigations, a oneto-one correspondence between the value of the expert language judgment variable and the intuitionistic fuzzy number is established to make the decision-making more objective and scientific.

(2) The comprehensive weight of the evaluation criteria is established. In the past, the evaluation criteria only considered subjective weights, which were highly dependent on the data obtained, and did not consider objective weights. In this paper, the SWARA method is used to determine the subjective weight of the evaluation criteria, and the method based on the normal distribution is used to determine the objective weight of the evaluation criteria. If the decision-maker is highly confident in the acquired data, assign a value with a more considerable subjective weight and a value with a smaller objective weight and vice versa.

(3) Enrich the research on the occupational health and safety risk management of cruise ship construction. The occupational health and safety management is 
mainly concentrated in petroleum and construction companies and is rarely used in shipbuilding companies. The construction of a cruise ship is occurring for the first time in China. Based on this, an improved intuitionistic fuzzy TOPSIS decision model was proposed and used in the occupational health and safety risk assessment of China's first cruise ship construction.

The structure of this article is as follows. Section 2 gives a literature review of this article. Section 3 introduces the related theories of intuitionistic fuzzy sets used in this article. Section 4 introduces the improved intuitionistic fuzzy TOPSIS decision model in detail. Section 5 takes a cruise ship under construction as an example. The intuitionistic fuzzy TOPSIS model is used to solve the risk assessment of occupational health and safety, and the sensitivity analysis is carried out. At the same time, the results are compared with the results of other model algorithms to verify the effectiveness and feasibility of the model and method. Section 6 gives the conclusions of this paper.

\section{Literature Review}

2.1. Occupational Health and Safety Risk Characteristics of Cruise Ship Construction. The construction of cruise ships and ordinary ships have significant characteristics, and their health and safety risks are mainly concentrated in three aspects. (1) The construction workload of the cabin area is large, and the risk of outdoor hoisting operations is high. The most significant difference between cruise ship construction and ordinary civil ships is that in the superstructure, the construction workload of the cruise ship cabin area is the most significant part of the ship, which is about twice the workload of the engine room equipment area. The entire construction period of a 100,000-ton luxury cruise ship is about 24 months, and the cabin construction and hoisting period is about 12-16 months. The outdoor lifting and hoisting activities of cruise ship construction have increased significantly, which puts forward higher requirements on the corresponding technology. The accompanying construction safety risks are also increasing. This has brought significant challenges to the shipyard's project management and put forward new requirements for occupational health and safety risk management during the construction process. (2) The cabins are dense, there are many flammable materials, and the risk of fire is high. There are many cabins and flammable items in luxury cruise ships. The construction of luxury cruise ships involves complex and large personnel, which puts forward higher requirements for safe production. The fire accident in the process of building cruise ships in Japanese shipyards is a painful lesson. In terms of safety production, Finland Aker Shipyard, one of the European luxury cruise shipbuilders, has adopted more advanced safety management technology in safety production management. When constructing the "Ocean Oasis," the plant adopted a personnel tracking and positioning system based on the Internet of Things technology to grasp the location information of 5,000 employees from more than 40 countries and more than a dozen companies in real time. The hazards of objects and personnel are minimized. (3) There are many painting operations on the hull's surface, and the discharge of toxic gases is high. Luxury cruise ships have high requirements for appearance design, and the amount of painting on the hull's surface of a luxury cruise ship is much higher than that of an ordinary civil ship. The resulting large amounts of toxic gases such as xylene and ethylbenzene have caused a certain environmental pressure, which will also require special attention during the construction process.

2.2. Selection of Occupational Health and Safety Risk Assessment Methods for Cruise Ship Construction. Risk management adheres to the concept of "prevention and continuous improvement". It has a high degree of selfdiscipline, self-improvement, and self-motivation mechanism. It is an essential part of the corporate culture, one of the core competitiveness of enterprises, and the unity of economic and social problems. Its purpose is to effectively prevent various injuries in construction operations during the implementation of the project, protect the safety and health of employees, prevent pollution and damage to the environment, and continuously improve the overall quality, work quality, management level, and products of the company's personnel quality and service quality, and so on. Risk assessment is the core process of risk management. At present, scholars have done a lot of research on risk assessment methods. However, there are relatively few studies on the risk assessment of occupational health and safety in ship construction or cruise ship construction. To assess the occupational health and safety risks objectively and reasonably in cruise ship construction, relevant evaluation models of other industries can be used for research and application in cruise ship construction's occupational health and safety risk assessment. Choi et al. [10] and others have studied risk interruption management, risk control, and logistics service risk management for logistics system risk management. Stefanovic et al. [11] and others recognized the importance of employee health and safety in many companies and proposed that efforts be made to establish an occupational hazard control system to improve employees' mental, physical, and safety levels. Through a 24 -week experiment, Helen Lingard [12] evaluated how first aid training affects employees in construction companies to avoid occupational injuries and occupational diseases and how it affects their occupational safety behaviors. The results show that first aid training can reduce employees' willingness to accept safety risks, increase their cognition probability of work-related injuries and occupational diseases, enhance employees' motivation to avoid occupational injuries and occupational diseases, and improve their risk control behavior. Joseph Gustin [13] mentioned that many factors cause accidents. An accident-free workplace is the result of multiple factors. By providing employees with a suitable environment, they will subconsciously pay attention to safety to reduce the possibility of accidents. Sellnow et al. [14] systematically described the identification and communication of risks in "Effective Risk Communication" 
TABLE 1: Comparison of risk assessment methods.

\begin{tabular}{|c|c|}
\hline Method & Features \\
\hline LEC evaluation method & Practical and straightforward but lacking flexibility and subjective \\
\hline Analytic network process (ANP) & $\begin{array}{l}\text { Reflects the dependence between the hierarchical structure but needs to study the relationship } \\
\text { between the factors; the workload is relatively large. }\end{array}$ \\
\hline TOPSIS method & Simple calculation, full use of original data, and less information loss, but strong subjectivity \\
\hline FMEA method & $\begin{array}{l}\text { Effectively determines failure modes and failure causes and predicts the types of failures that may } \\
\text { occur; however, the connection between the various units of the system is not considered. }\end{array}$ \\
\hline Monte Carlo method (MCM) & $\begin{array}{l}\text { The algorithm is simple, and the process is flexible; however, the amount of data is large, and the } \\
\text { data requirements are strict. }\end{array}$ \\
\hline $\begin{array}{l}\text { Artificial neural network (ANN) } \\
\text { method }\end{array}$ & Has strong self-learning ability and avoids artificial setting of weights, but takes longer time. \\
\hline Analytic hierarchy process (AHP) & $\begin{array}{l}\text { Comprehensive consideration of qualitative and quantitative. However, when there are too many } \\
\text { indicators, the data statistics are large. The weight of the indicators is difficult to determine. }\end{array}$ \\
\hline $\begin{array}{l}\text { Fuzzy comprehensive evaluation } \\
\text { (FCE) method }\end{array}$ & $\begin{array}{l}\text { According to the membership degree theory of fuzzy mathematics, the qualitative evaluation is } \\
\text { transformed into a quantitative evaluation method. The result is clear and systematic, suitable for } \\
\text { solving nondeterministic problems, but the calculation is complex and subjective. }\end{array}$ \\
\hline
\end{tabular}

because our work and living spaces are connected. The book describes various good practices for establishing effective risk communication. It has also played a significant reference role in our safety production management. Loranger and Zayed [15] evaluated environmental and occupational exposure to manganese and its oxides. Manganese and its oxides are incredibly harmful to the human body. The situation is dire in electric welding operations. Ventilation should be strengthened to reduce its harm to the human body. Ismail et al. [16] studied the correlation between the incidence of occupational hazards of construction workers and their attention to safety. The survey objects involved construction workers in high-rise buildings, infrastructure construction workers, and ordinary residential construction workers, with a sample size of 275 . Their research found that the most influential safety factor is the construction workers' safety awareness, followed by mutual communication, that is, the surrounding safety atmosphere, and put forward that the safety of construction enterprises can improve the safety management level of enterprises by improving the optimization and transformation of equipment, improving the work process and informing workers of potential safety hazards. The commonly used risk assessment methods include the expert assessment method, decision tree analysis method, Monte Carlo method, artificial neural network method, analytic hierarchy process, fuzzy comprehensive evaluation method, and so on [17-23]. Table 1 shows the comparison of various risk assessment methods.

As shown in Table 1, many models based on the MCDM have been proposed. However, an improved intuitionistic fuzzy TOPSIS decision model has not yet been proposed to assess cruise ship construction's occupational health and safety risks. Considering that intuitionistic fuzzy sets can handle the extreme ambiguity and uncertainty in risk assessment and the sufficiency of the TOPSIS method to process data, this paper combines and improves them. When dealing with the subjective weights of evaluation criteria, a new multicriteria decision-making method based on evaluation criteria is adopted, namely, the SWARA method. To eliminate the influence of subjective weight data with large deviation on the final results, a method based on normal distribution is introduced to determine the objective weight of the evaluation criteria. Finally, an example analysis proves the validity and stability of the decision-making model.

\section{The Basic Theory of Intuitionistic Fuzzy Sets}

Definition 1 (see [4]). Assume $X$ is a nonempty set, given a mapping

$$
\begin{aligned}
f_{A}: X & \longrightarrow[0,1] \times[0,1], \\
x & \mapsto\left(\mu_{A}(x), v_{A}(x)\right),
\end{aligned}
$$

where $0 \leq \mu_{A}(x)+v_{A}(x) \leq 1$, then $f_{A}$ determines an intuitionistic fuzzy set of nonempty sets $X$, denoted as $A=\left\{\left\langle x, \mu_{A}(x), v_{A}(x)\right\rangle \mid x \in X\right\}$, where $\mu_{A}(x)$ is the membership function and $\nu_{A}(x)$ is the nonmembership function, so that $\pi_{A}(x)=1-\mu_{A}(x)-v_{A}(x) \pi_{A}(x)$ denotes the degree of hesitation or uncertainty in which an element $x$ belongs $A$.

Definition 2 (see [24]). Let $\alpha_{j}=\left(\mu_{j}, v_{j}\right)(j=1,2, \ldots, n)$ be a set of intuitionistic fuzzy numbers (IFNs) and $\omega=\left(\omega_{1}, \omega_{2}, \ldots, \omega_{n}\right)^{T}$ be its weight vector, and if $\sum_{j=1}^{n} \omega_{j}=1, \omega_{j} \in[0,1]$, then IFWA the (intuitionistic fuzzy weighted averaging) operator is as follows:

$$
\begin{aligned}
\operatorname{IFWA}\left(\alpha_{1}, \alpha_{2}, \ldots, \alpha_{n}\right) & =\bigoplus_{j=1}^{n} \omega_{j} \alpha_{j} \\
& =\left(1-\prod_{j=1}^{n}\left(1-\mu_{j}\right)^{\omega_{j}}, \prod_{j=1}^{n} v_{j}^{\omega_{j}}\right) .
\end{aligned}
$$

Definition 3 (see [25]). For any intuitionistic fuzzy number $\alpha=(\mu, \nu)$ and the score function is defined as follows:

$$
S(\alpha)=\mu-v,
$$

where $S(\alpha) \in[-1,1]$. 
Definition 4 (see [26]). Improve the score function of Definition 3. For any intuitionistic fuzzy number $\alpha=(\mu, \nu)$, the improved score function is defined as follows:

$$
S^{*}(\alpha)=\frac{S(\alpha)+1}{2} \text {. }
$$

At this time, $S^{*}(\alpha) \in[0,1]$.

Definition 5 (see [27]). Let $\alpha_{1}=\left(\mu_{1}, \nu_{1}\right), \alpha_{2}=\left(\mu_{2}, \nu_{2}\right)$ be any two intuitionistic fuzzy numbers, IFD (intuitionistic fuzzy distance) operator of intuitionistic fuzzy numbers $\alpha_{1}$ and $\alpha_{2}$ for

$$
d_{\mathrm{IFD}}\left(\alpha_{1}, \alpha_{2}\right)=\left|\alpha_{1}-\alpha_{2}\right|=\frac{1}{2}\left(\left|\mu_{1}-\mu_{2}\right|+\left|v_{1}-v_{2}\right|\right) .
$$

Definition 6 (see [28]). Let $\alpha_{j}=\left(\mu_{j}, v_{j}\right), \beta_{j}=\left(\mu_{j}^{\prime}, v_{j}^{\prime}\right)(j=$ $1,2, \ldots, n)$ be two sets of intuitionistic fuzzy numbers. If Intuitionistic fuzzy weighted Euclidean distance (IFWED) operator is a mapping: $\Omega^{n} \times \Omega^{n} \longrightarrow R$, they are represented as follows:

$$
\operatorname{IFWED}(\alpha, \beta)=\left\{\sum_{i=1}^{n} \omega_{i}\left[d_{\mathrm{IFD}}\left(\alpha_{i}, \beta_{i}\right)\right]^{2}\right\}^{1 / 2},
$$

where $\omega=\left(\omega_{1}, \omega_{2}, \ldots, \omega_{n}\right)^{T}$ is the weight vector and $\sum_{j=1}^{n} \omega_{j}=1, \omega_{j} \in[0,1]$.

Definition 7 (see [28]). Let $\alpha_{j}=\left(\mu_{j}, v_{j}\right), \beta_{j}=\left(\mu_{j}^{\prime}, v_{j}^{\prime}\right)(j=$ $1,2, \ldots, n)$ be two sets of intuitionistic fuzzy numbers (IFNs). If the IFOWED operator is a mapping: $\Omega^{n} \times$ $\Omega^{n} \longrightarrow R$, there is

$$
\operatorname{IFOWED}(\alpha, \beta)=\left\{\sum_{j=1}^{n} \omega_{j}\left[d_{\mathrm{IFD}}\left(\alpha_{\sigma(j)}, \beta_{\sigma(j)}\right)\right]^{2}\right\}^{1 / 2} .
$$

Among them, $\omega=\left(\omega_{1}, \omega_{2}, \ldots, \omega_{n}\right)^{T}$ is the weight vector and $\sum_{j=1}^{n} \omega_{j}=1, \omega_{j} \in[0,1] .[\sigma(1), \sigma(2), \ldots, \sigma(n)]$ is any permutation of $\{1,2, \ldots, n\}$, which is

$$
d_{\mathrm{IFD}}\left[\alpha_{\sigma(j-1)}, \beta_{\sigma(j-1)}\right] \geq d_{\mathrm{IFD}}\left[\alpha_{\sigma(j)}, \beta_{\sigma(j)}\right], \quad j \in\{1,2, \ldots, n\} .
$$

Using equation (5), equation (8) can be determined.

\section{Improved Intuitionistic Fuzzy TOPSIS Decision Model}

Due to the complexity and uncertainty of the cruise ship construction system and the lack of knowledge or data in the problem area, it is challenging to use accurate numbers to evaluate risk factors. Based on this, the actual survey conducted during the internship of the shipbuilding company, based on the knowledge and experience and the actual needs of the cruise ship construction occupational health and safety risk assessment, and the questionnaires between the linguistic variable values and the intuitionistic fuzzy numbers (IFNs) are established in Tables 2 and 3. Decisionmaking experts express the degree of preference based on the
TABLE 2: Correspondence between the risk source level and IFNs.

\begin{tabular}{lc}
\hline Linguistic variables & IFNs \\
\hline Extremely low (EL) & $(0.05,0.95)$ \\
Very low (VL) & $(0.15,0.80)$ \\
Low (L) & $(0.25,0.70)$ \\
Slightly lower (ML) & $(0.35,0.60)$ \\
Medium (M) & $(0.50,0.45)$ \\
Slightly higher (MH) & $(0.65,0.30)$ \\
High (H) & $(0.75,0.20)$ \\
Very high (VH) & $(0.85,0.10)$ \\
Extremely high (EH) & $(0.95,0.05)$ \\
\hline
\end{tabular}

TABLE 3: Correspondence between the evaluation criteria level and IFNs.

\begin{tabular}{lc}
\hline Linguistic variables & IFNs \\
\hline Extremely important (ES) & $(0.90,0.05)$ \\
Very important (VS) & $(0.80,0.15)$ \\
Important (S) & $(0.65,0.30)$ \\
Middle (M) & $(0.50,0.45)$ \\
Not important (U) & $(0.35,0.60)$ \\
Very unimportant (VU) & $(0.20,0.75)$ \\
Extremely unimportant (EU) & $(0.10,0.90)$ \\
\hline
\end{tabular}

intuitionistic fuzzy numbers corresponding to Tables 2 and 3. The reason why intuitionistic fuzzy numbers are used in this paper is that they can express the preferences of decision-makers from three aspects: membership degree, nonmembership degree, and hesitation degree and can describe the ambiguity and uncertainty more comprehensively. Based on this, an improved intuitionistic fuzzy TOPSIS decision model was constructed to evaluate and rank the risk sources of occupational health and safety of cruise ship construction, and the objective weight of risk evaluation criteria was introduced to eliminate the influence of subjective weight data with significant deviation on the integrated result.

The TOPSIS (technique for order preference by similarity to ideal solution) method was first proposed by Hwang CL and Yoon K. The idea is as follows: the selected optimal solution should be as close as possible to the positive-ideal solution and far away from the negative-ideal solution as much as possible. However, the traditional TOPSIS method is too subjective. To calculate the total weight of the evaluation criteria, the SWARA method is used to calculate the subjective weight, and the normal distribution method is used to calculate the objective weight. The essence of objective weight calculated based on normal distribution is to give a smaller objective weight to the risk evaluation criteria with too large or too small subjective weight to minimize the impact of extensive data on the final results [29]. The calculation steps of the improved intuitionistic fuzzy TOPSIS decision model are the same as those of the TOPSIS decision model. The flowchart of the improved intuitionistic fuzzy TOPSIS decision model is shown in Figure 1.

Step 1: determine the occupational health and safety risk sources, risk evaluation criteria, and decisionmaking expert group. 


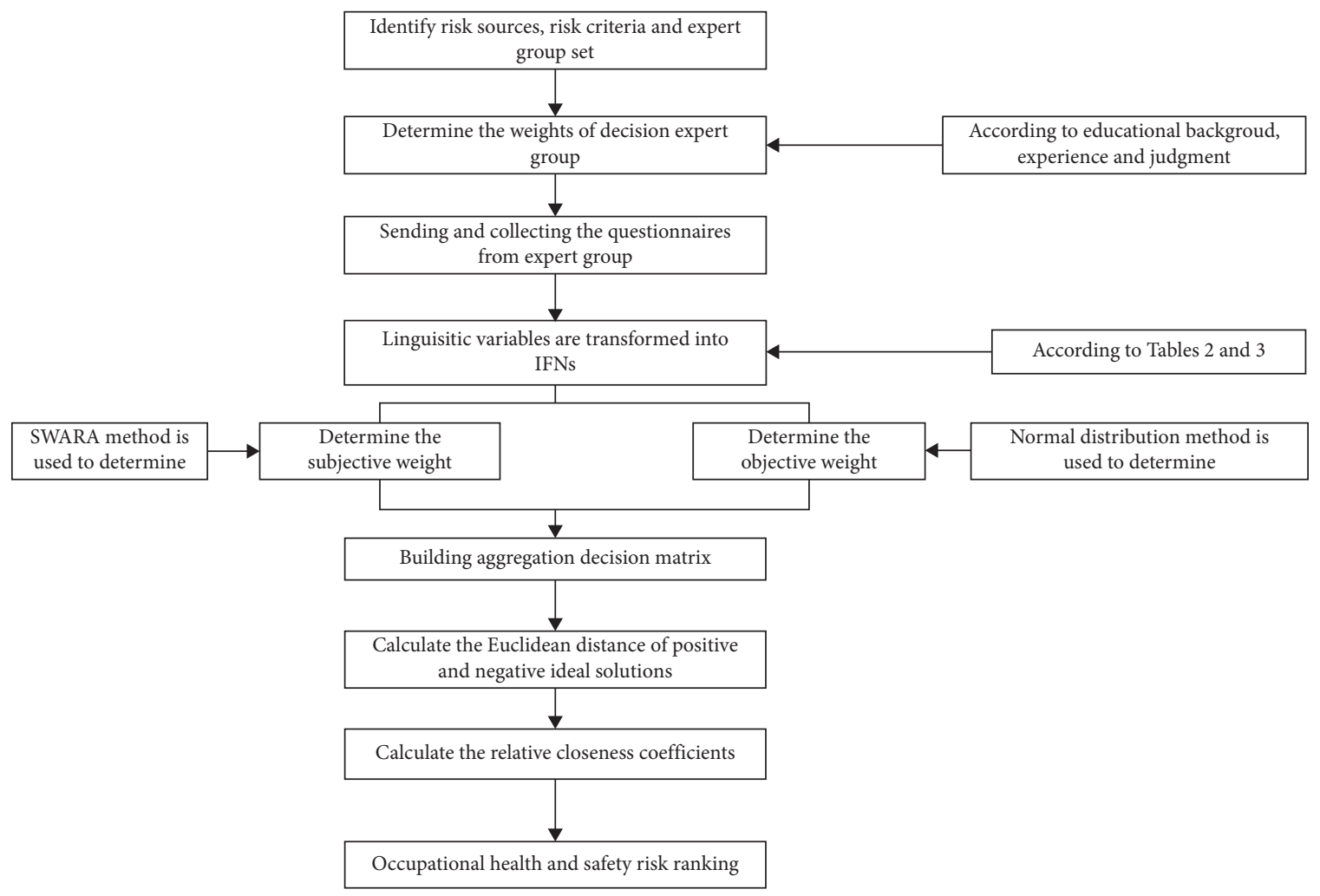

FIGURE 1: Flowchart of the improved intuitionistic fuzzy TOPSIS decision model.

The risk source set of occupational health and safety in cruise ship construction is $H=\left\{H_{1}, H_{2}, \ldots, H_{m}\right\}$. The set of risk evaluation criteria is $C=\left\{C_{1}, C_{2}, \ldots, C_{n}\right\}$, and its weight vectors are $\lambda=\left(\lambda_{1}, \lambda_{2}, \ldots, \lambda_{n}\right)^{T}$. The set of the invited expert group is $E=\left\{E_{1}, E_{2}, \ldots, E_{p}\right\}$, and its weight vector is $\omega=\left(\omega_{1}, \omega_{2}, \ldots, \omega_{p}\right)^{T}$.

Step 2: determine the weights of the decision-making expert group.

The decision-making expert group consists of $p$ experts. The weight of $p$ experts is $\omega=\left(\omega_{1}, \omega_{2}, \ldots, \omega_{p}\right)^{T}$, which is objectively determined based on their relative importance.

Step 3: send the questionnaires Tables 2 and 3 and summarize the results of the tables.

The construction of a cruise ship is the first time, and historical data are lacking. This article uses the expert survey method to obtain questionnaires. The expert survey method is also called the Delphi method. The questionnaires Tables 2 and 3 are sent to the members of the decision-making expert group by e-mail. Members of the expert group cannot communicate with each other. They can only rely on the feedback information provided by the organizer to fill in the questionnaire. This is done to ensure the scientific and independence of the questionnaire table.

Step 4: establish an intuitionistic fuzzy risk aggregation decision matrix.
Based on the summary evaluation results of questionnaire Table 2 in step 3, establish the intuitionistic fuzzy risk aggregation decision matrix $R$ :

$$
R=\left[\begin{array}{cccc}
r_{11} & r_{12} & \cdots & r_{1 n} \\
r_{21} & r_{22} & \cdots & r_{2 n} \\
\cdots & \cdots & \cdots & \cdots \\
r_{m 1} & r_{m 2} & \cdots & r_{m n}
\end{array}\right] .
$$

$r_{i j}=\operatorname{IFWA}\left(z_{i j}^{(1)}, z_{i j}^{(2)}, \ldots, z_{i j}^{(p)}\right)=\omega_{1} * z_{i j}^{(1)} \oplus \omega_{2} * z_{i j}^{(2)} \oplus$ $\cdots \oplus \omega_{p} * z_{i j}^{(p)}=\left(1-\prod_{k=1}^{p}\left(1-\mu_{i j}^{(k)}\right)^{\omega_{k}}, \prod_{k=1}^{p}\left(v_{i j}^{(k)}\right)^{\omega_{k}}\right)$, among them, $z_{i j}^{(k)}=\left(\mu_{i j}^{(k)}, v_{i j}^{(k)}\right) . z_{i j}^{(k)}(k=1,2, \ldots, p)$ denotes the intuitionistic fuzzy number of the $k-$ th expert independently evaluating when the risk source $i$ corresponds to the evaluation criteria $j . m$ and $n$, respectively, represent the number of risk sources and evaluation criteria.

Step 5: determine the subjective weight of risk evaluation criteria.

The SWARA (stepwise weight assessment ratio analysis) method is a new MCDM method for determining subjective weights proposed by Kersuliene [30, 31]. The intuitionistic fuzzy set theory is unified with the SWARA method, namely the intuitionistic fuzzy SWARA method. The specific steps for determining the subjective weight are the same as the SWARA method, which are as follows: 
Step 5.1: the ranking of evaluation criteria: according to the questionnaire Table 3 in step 3, each decisionmaker expresses the relative importance of each evaluation criteria according to the corresponding intuitionistic fuzzy numbers. Then, the aggregation intuitionistic fuzzy number of each evaluation criteria is obtained using equation (2), and the score function value of each evaluation criteria is obtained using equation (4). According to the score function value of each evaluation criteria, the order is from large to small. Step 5.2: determine the relative importance-related parameters $s_{j}(j \geq 2)$ of two adjacent evaluation criteria. From the second criterion to the last criterion, the association parameter $s_{j}(j \geq 2)$ is determined according to specific rules. In this paper, the difference between the score function values of two adjacent evaluation criteria is taken as the association parameter.

Step 5.3: calculate the comparison coefficient $k_{j}$ according to the following equation:

$$
k_{j}= \begin{cases}1, & j=1, \\ s_{j}+1, & j>1 .\end{cases}
$$

Step 5.4: calculate the relative weight $q_{j}$ according to the following equation:

$$
q_{j}= \begin{cases}1, & j=1, \\ \frac{q_{j-1}}{k_{j}}, & j>1 .\end{cases}
$$

Step 5.5: calculate the final subjective weight $\lambda_{j}$ according to the following equation:

$$
\lambda_{j}=\frac{q_{j}}{\sum_{k=1}^{n} q_{k}} .
$$

Step 6: determine the objective weight of risk evaluation criteria.

Ordered weighted aggregation (OWA) operator is defined as a mapping: $R^{n} \longrightarrow R$. The weighted vector element $\bar{\lambda}=\left(\bar{\lambda}_{1}, \bar{\lambda}_{2}, \ldots, \bar{\lambda}_{n}\right)^{T} \quad$ and $\bar{\lambda}_{1}+\bar{\lambda}_{2}+\cdots+\bar{\lambda}_{n}=1$, such that

$$
\operatorname{OWA}\left(a_{1}, a_{2}, \ldots, a_{n}\right)=\sum_{j=1}^{n} \bar{\lambda}_{j} b_{j}
$$

where $b_{j}$ is the $j-$ th largest number in $a_{i}(i=1,2, \ldots, n)$, that is, $b_{1} \geq b_{2} \geq \cdots \geq b_{n}$.

The main advantage of OWA operators is the descending order. The key point of the OWA operator is how to determine the OWA weight. In this paper, the normal distribution method of literature [32] is adopted. According to its method, the objective weight is obtained using equations (14)-(16). Its essence is to give it a small objective weight for the risk evaluation criteria that are too large or too small in the subjective weight to minimize the impact of more extensive data on the final result.

$$
\begin{aligned}
\bar{\lambda}_{j} & =\frac{1}{\sqrt{2 \pi} \sigma_{n}} e^{-\left[\left(j-\mu_{n}\right)^{2} /\left(2 \sigma_{n}^{2}\right)\right]}, \quad j \in\{1,2, \ldots, n\}, \\
\mu_{n} & =\frac{1}{n} \frac{n(1+n)}{2}=\frac{1+n}{2} \\
\sigma_{n} & =\left[\frac{1}{n} \sum_{j=1}^{n}\left(j-\mu_{n}\right)^{2}\right]^{1 / 2},
\end{aligned}
$$

where $\mu_{n}$ represents the arithmetic mean of the set $\{1,2, \ldots, n\} . \sigma_{n}$ is the standard deviation of the set $\{1,2, \ldots, n\} . \bar{\lambda}=\left(\bar{\lambda}_{1}, \bar{\lambda}_{2}, \ldots, \bar{\lambda}_{n}\right)$ represents the objective weight.

Step 7: calculate the Euclidean distance between each risk source and the positive-ideal solution and the negative-ideal solution.

Let the intuitionistic fuzzy number $\alpha^{+}=(1,0)$ represent a negative-ideal solution and $\alpha^{-}=(0,1)$ represent a positive-ideal solution. When the intuitionistic fuzzy number of each risk source is closer to $\alpha^{-}$, the risk level is lower; and when it is closer to $\alpha^{+}$, the risk level is higher. According to equation (5), the positive-ideal solution distance of the risk evaluation criterion corresponding to each risk source $F_{i j}^{+}$and negative-ideal solution distance $F_{i j}^{-}$can be obtained, which is

$F_{i j}^{+}=d_{\mathrm{IFD}}\left(r_{i j}, \alpha^{-}\right), \quad i \in\{1,2, \ldots, m\}, j \in\{1,2, \ldots, n\}$,

$F_{i j}^{-}=d_{\mathrm{IFD}}\left(r_{i j}, \alpha^{+}\right), \quad i \in\{1,2, \ldots, m\}, j \in\{1,2, \ldots, n\}$,

where $r_{i j}$ is given by equation (9).

Let the subjective weight ratio be $\phi$ and the objective weight ratio be $1-\phi$. According to equation (6), the ideal solution distance of subjective weight can be obtained. Based on equation (7), the ideal solution distance with objective weights can be obtained. According to equations (17) and (18), each risk source's positive-ideal solution distance can be obtained with negative-ideal solution distance, fully considering the subjective weight and objective weight to be closer to the actual situation.

$$
D_{i}^{+}=\phi\left\{\sum_{j=1}^{n} \lambda_{j}\left[d_{\mathrm{IFD}}\left(r_{i j}, \alpha^{-}\right)\right]\right\}^{1 / 2}+(1-\phi)\left\{\sum_{j=1}^{n} \bar{\lambda}_{j}\left[d_{\mathrm{IFD}}\left(r_{i \sigma(j)}, \alpha^{-}\right)\right]\right\}^{1 / 2},
$$




$$
D_{i}^{-}=\phi\left\{\sum_{j=1}^{n} \lambda_{j}\left[d_{\mathrm{IFD}}\left(r_{i j}, \alpha^{+}\right)\right]\right\}^{1 / 2}+(1-\phi)\left\{\sum_{j=1}^{n} \bar{\lambda}_{j}\left[d_{\mathrm{IFD}}\left(r_{i \sigma(j)}, \alpha^{+}\right)\right]\right\}^{1 / 2},
$$

where $\left(\sigma_{(1)}, \sigma_{(2)}, \ldots, \sigma_{(n)}\right)$ belong a permutation of $\{1,2, \ldots, n\}$. In equation (19), there is $d_{\mathrm{IFD}}$ $\left[r_{i \sigma(j-1)}, \alpha^{-}\right] \geq d_{\mathrm{IFD}}\left[r_{i \sigma(j)}, \alpha^{-}\right]$; in equation (20), there is $d_{\mathrm{IFD}}\left[r_{i \sigma(j-1)}, \alpha^{+}\right] \geq d_{\mathrm{IFD}}\left[r_{i \sigma(j)}, \alpha^{+}\right], j \in\{1,2, \ldots, n\}$. Step 8: determine the priority of risk sources.

According to equation (21), calculate the relative closeness coefficient $G_{i}$ between risk source $H_{i}$ and positiveideal solution $\alpha^{-}=(0,1)$.

$$
G_{i}=\frac{D_{i}^{-}}{D_{i}^{+}+D_{i}^{-}}
$$

According to the relative closeness coefficient $G_{i}(i=1,2, \ldots, m)$, the risk sources can be ranked from low to high. The highest $G_{i}$ value represents that the harm of the former is the lowest at present; the lowest $G_{i}$ value represents the highest harm at present, which must be paid great attention to.

\section{Occupational Health and Safety Risk Assessment of Cruise Ship Construction}

5.1. Problem Description. Take the construction of a cruise ship as an example to verify the usability and practicability of the occupational health and safety risk assessment decisionmaking model. In cruise ship construction, occupational health and safety risk management refers to the scientific management theory of identifying, analyzing, and evaluating risks in the production process to control risks to achieve the best production guarantee effectively. Generally speaking, there are two main objectives of risk management: one is to identify apparent and potential risks and deal with and control risks based on risk assessment to reduce losses and the other is to provide as much as possible after losses occur. Emergency measures are taken to reduce the harmfulness of the loss. According to the occupational health and safety system standards and the relevant national requirements on occupational health, safety, and environmental management, the identification of hazardous factors should follow the following principles. (1) The principle of legality. When identifying hazards, national laws, regulations, and related standards are mainly implemented to meet and comply with the requirements of laws, regulations, and standards. At the same time, national laws, regulations, and standards are used as an essential basis for identifying hazardous factors. (2) System principle. Systemic means that the identification of hazardous factors is a systematic and comprehensive work. In terms of space, hazard identification should be carried out for all activities, products, and service processes in the organization, covering all departments, positions, and workplaces of the organization, including all processes; in terms of time, hazard identification is a continuous process. It should be carried out regularly. The possible hazards in the past, present, and future should be identified; for business areas, there are both service areas and production and operation areas; for cruise ship construction, it should include production; transportation; storage; and sales, use, abandonment, and disposal. (3) The principle of full participation. Full participation is a basic idea of occupational health and safety management; it is also a duty of employees, and it is also the implementation of employees' "right to know." Management personnel at all levels and essential operation staff have knowledge and experience of on-site operations, and full participation can ensure "systematisms." (4) Scientific principles. Scientific means that the identification of hazard factors should pay attention to scientific principles such as accident theory, safety engineering theory, and system theory for guidance to ensure that hazard factors are not overlooked and improve work efficiency. Based on field surveys and empirical data analysis conducted by shipbuilding companies based on legality, systematicity, full participation, and scientific principles, a total of 14 risk sources in occupational health and safety have been identified. The results are shown in Table 4. Shipbuilding companies have selected five experienced decision-making experts, all of whom have been engaged in the occupational health and safety industry for more than 10 years. Five decision-making experts determined three risk evaluation criteria: risk severity $\left(C_{1}\right)$, risk probability $\left(C_{2}\right)$, and risk uncontrollability $\left(C_{3}\right)$. The risk severity $\left(C_{1}\right)$ indicates the loss of cost, quality, and time caused by the risk source; the probability of risk $\left(C_{2}\right)$ indicates the probability of the source of risk; the uncontrollability of risk $\left(C_{3}\right)$ indicates the extent to which the risk source cannot be controlled. The management questionnaires Tables 2 and 3 (see Section 4) for evaluating risk sources and risk evaluation criteria will be independently sent to these five experienced decisionmakers to avoid interference by other experts when scoring to ensure the management questionnaire results and independence.

\subsection{Risk Assessment}

Step 1: identify risk sources, evaluation criteria, and the decision-making expert group.

The set of risk sources is $H=\left\{H_{1}, H_{2}, \ldots, H_{14}\right\}$. The set of risk evaluation criteria is $C=\left\{C_{1}, C_{2}, C_{3}\right\}$, and its weight vector is $\lambda=\left(\lambda_{1}, \lambda_{2}, \lambda_{3}\right)^{T}$. The set of decisionmaking expert groups is $E=\left\{E_{1}, E_{2}, \ldots, E_{5}\right\}$, and its weight vector is $\omega=\left(\omega_{1}, \omega_{2}, \ldots, \omega_{5}\right)^{T}$.

Step 2: determine the weights of the decision-making expert group.

The weights of the five decision-making experts are objectively determined based on their relative importance, such as working years, educational level, 
TABLE 4: Sources of occupational health and safety risks in cruise ship construction.

\begin{tabular}{lc}
\hline No. & Hazards \\
\hline$H_{1}$ & Equipment failure \\
$H_{2}$ & Equipment mechanization level \\
$H_{3}$ & Insufficient security investment \\
$H_{4}$ & Emsufficient protective equipment for employees \\
$H_{5}$ & Employee fatigue and overwork \\
$H_{6}$ & Warning signs are not properly posted \\
$H_{7}$ & Exposure to toxic and hazardous substances \\
$H_{8}$ & Insufficient employee safety training \\
$H_{9}$ & Employee hot work \\
$H_{10}$ & Unsafe behavior of employees \\
$H_{11}$ & Unsafe behavior of technical management \\
$H_{12}$ & Noise hazards \\
$H_{13}$ & Electromagnetic radiation \\
$H_{14}$ & Employees with certificates \\
\hline
\end{tabular}

judgment, work area, and so on. The specific weight results are shown in Table 5. Hence, the weight of the expert group is $\omega=(0.24,0.20,0.30,0.15,0.11)^{T}$.

Step 3: send the questionnaires Tables 2 and 3 and summarize the results of the tables.

First, make an appointment by phone with the decision-making expert group and then send the questionnaires Tables 2 and 3 to the expert group by e-mail. The expert group members cannot communicate with each other to avoid interference from other experts when scoring. They can only fill out the questionnaire based on the feedback provided to ensure the scientificity and independence of the management questionnaires Tables 2 and 3.

Step 4: establish an intuitionistic fuzzy aggregate decision matrix for risk sources.

According to the evaluation results summarized in the questionnaire Table 2 in step 3, Table 6 is obtained. According to equation (2), the intuitionistic fuzzy aggregation decision matrix of risk sources is obtained as equation (7), and the relevant data are shown in Table 7.

Step 5: determine the subjective weight of risk evaluation criteria.

According to the evaluation results summarized in the questionnaire Table 2 in step 3, Table 8 is obtained. According to equations (8)-(13), the subjective weight of the evaluation criteria is obtained, and the results are
TABLE 5: Relative importance weights of the five experts.

\begin{tabular}{lcccc}
\hline No. & $\begin{array}{c}\text { Working } \\
\text { years }\end{array}$ & $\begin{array}{c}\text { Education } \\
\text { level }\end{array}$ & Job field & Weights \\
\hline Expert 1 & 15 & $\mathrm{PhD}$ & $\begin{array}{c}\text { Safety } \\
\text { engineering }\end{array}$ & 0.24 \\
Expert 2 & 24 & $\mathrm{MSc}$ & $\begin{array}{c}\text { Safety } \\
\text { engineering } \\
\text { Safety }\end{array}$ & 0.20 \\
Expert 3 & 25 & $\mathrm{PhD}$ & $\begin{array}{c}\text { Sagineering } \\
\text { enginety }\end{array}$ & 0.30 \\
Expert 4 & 20 & MSc & $\begin{array}{c}\text { Safety } \\
\text { engineering } \\
\text { Safety }\end{array}$ & 0.15 \\
Expert 5 & 14 & MSc & $\begin{array}{c}\text { engineering } \\
\text { engine }\end{array}$ & \\
\hline
\end{tabular}

shown in Table 9. According to Table 9, the subjective weight is $\lambda=(0.3782,0.3292,0.2926)^{T}$.

Step 6: determine the objective weight of risk evaluation criteria.

According to step 1, risk evaluation criteria $n=3$. According to equations (14) to (16), $\mu_{3}=2, \sigma_{3}=\sqrt{1.5}$, $\bar{\lambda}_{1}=0.2429, \bar{\lambda}_{2}=0.5142, \bar{\lambda}_{3}=0.2429$. Therefore, the objective weight of the risk criterion is $\bar{\lambda}=(0.2429,0.5142,0.2429)^{T}$.

Step 7: calculate the Euclidean distance between each risk source and the positive-ideal solution and the negative-ideal solution.

According to equations (17) and (18), find the positiveideal solution and negative-ideal solution of the risk evaluation criterion corresponding to each risk source. In equations (19) and (20), according to equation (9), the risk evaluation criterion $C_{1}$ is assigned with an objective weight of $0.2429, C_{2}$ is assigned with an objective weight of 0.5142 , and $C_{3}$ is assigned with an objective weight of 0.2429 . Its essence is to give a small objective weight to the risk evaluation criteria that are too large or too small in the subjective weight to minimize the impact of more extensive data on the results. According to equations (16) and (17), the Euclidean distance of the positive-ideal solution and the negative-ideal solution of each risk source can be obtained. The calculation results are shown in Table 10.

Step 8: determine the priority of risk sources.

According to equation (21), we can get the relative closeness coefficient $G_{i}$. According to $G_{i}(i=1,2, \ldots, 14)$, risk sources are ranked from small to large

$$
H_{8}<H_{10}<H_{12}<H_{11}<H_{7}<H_{13}<H_{4}<H_{5}<H_{6}<H_{9}<H_{2}<H_{1}<H_{3}<H_{14} .
$$

The results indicate that employees with certificates $\left(H_{14}\right)$, insufficient security investment $\left(H_{3}\right)$, equipment failure $\left(H_{1}\right)$ are the lowest; insufficient employee safety training $\left(H_{8}\right)$, unsafe behavior of employees $\left(H_{10}\right)$, noise hazards $\left(H_{12}\right)$ are the highest. Shipbuilding companies should attach great importance to them..
5.3. Comparative Analysis. To verify the validity and rationality of this decision-making model, the method proposed in this paper is compared with the calculation results of the traditional TOPSIS, fuzzy TOPSIS method [33], and fuzzy MOORA method [34]. The risk ranking results of the four methods are shown in Table 11. According to Table 11, 
TABLE 6: Assessment summary of risk sources by the five experts.

\begin{tabular}{|c|c|c|c|c|c|c|c|c|c|c|c|c|c|c|c|}
\hline \multirow{2}{*}{ Expert } & \multirow{2}{*}{ Criteria } & \multicolumn{14}{|c|}{ Risk sources } \\
\hline & & $H_{1}$ & $\mathrm{H}_{2}$ & $\mathrm{H}_{3}$ & $H_{4}$ & $H_{5}$ & $H_{6}$ & $\mathrm{H}_{7}$ & $H_{8}$ & $H_{9}$ & $H_{10}$ & $H_{11}$ & $H_{12}$ & $H_{13}$ & $H_{14}$ \\
\hline \multirow{3}{*}{$E_{1}$} & $C_{1}$ & $\mathrm{VL}$ & ML & $\mathrm{VL}$ & ML & ML & $\mathrm{M}$ & $\mathrm{H}$ & $\mathrm{VH}$ & $\mathrm{L}$ & $\mathrm{EH}$ & $\mathrm{H}$ & $\mathrm{H}$ & $\mathrm{M}$ & $\mathrm{L}$ \\
\hline & $C_{2}$ & $\mathrm{~L}$ & $\mathrm{VL}$ & EL & $\mathrm{ML}$ & $\mathrm{MH}$ & $\mathrm{L}$ & $\mathrm{VH}$ & $\mathrm{VH}$ & ML & $\mathrm{H}$ & $\mathrm{MH}$ & M & $\mathrm{L}$ & EL \\
\hline & $C_{3}$ & EL & $\mathrm{EL}$ & $\mathrm{VL}$ & ML & ML & $\mathrm{M}$ & $\mathrm{H}$ & $\mathrm{VH}$ & $\mathrm{L}$ & $\mathrm{H}$ & MH & $\mathrm{H}$ & $\mathrm{MH}$ & EL \\
\hline \multirow{3}{*}{$E_{2}$} & $C_{1}$ & EL & $\mathrm{L}$ & $\mathrm{VL}$ & $\mathrm{ML}$ & $\mathrm{L}$ & $\mathrm{MH}$ & $\mathrm{MH}$ & $\mathrm{H}$ & $\mathrm{L}$ & $\mathrm{H}$ & $\mathrm{MH}$ & $\mathrm{VH}$ & $\mathrm{MH}$ & $\mathrm{L}$ \\
\hline & $C_{2}$ & ML & ML & $\mathrm{VL}$ & ML & $\mathrm{M}$ & ML & $\mathrm{MH}$ & $\mathrm{MH}$ & M & $\mathrm{MH}$ & $\mathrm{H}$ & $\mathrm{H}$ & $\mathrm{L}$ & VL \\
\hline & $C_{3}$ & EL & $\mathrm{VL}$ & EL & $\mathrm{M}$ & $\mathrm{L}$ & $\mathrm{M}$ & $\mathrm{MH}$ & $\mathrm{H}$ & $\mathrm{L}$ & $\mathrm{MH}$ & $\mathrm{H}$ & $\mathrm{H}$ & $\mathrm{M}$ & EL \\
\hline \multirow{3}{*}{$E_{3}$} & $C_{1}$ & EL & VL & $\mathrm{VL}$ & $\mathrm{M}$ & ML & ML & $\mathrm{M}$ & $\mathrm{EH}$ & $\mathrm{L}$ & $\mathrm{H}$ & $\mathrm{MH}$ & $\mathrm{VH}$ & $\mathrm{M}$ & VL \\
\hline & $C_{2}$ & $\mathrm{VL}$ & VL & VL & ML & $\mathrm{M}$ & $\mathrm{L}$ & $\mathrm{H}$ & $\mathrm{H}$ & $\mathrm{MH}$ & $\mathrm{H}$ & $\mathrm{H}$ & $\mathrm{MH}$ & ML & EL \\
\hline & $C_{3}$ & EL & $\mathrm{VL}$ & $\mathrm{VL}$ & ML & $\mathrm{L}$ & ML & $\mathrm{MH}$ & $\mathrm{H}$ & VL & $\mathrm{H}$ & MH & $\mathrm{MH}$ & $\mathrm{M}$ & VL \\
\hline \multirow{3}{*}{$E_{4}$} & $C_{1}$ & EL & $\mathrm{VL}$ & $\mathrm{L}$ & $\mathrm{MH}$ & $\mathrm{L}$ & $\mathrm{ML}$ & $\mathrm{M}$ & $\mathrm{M}$ & $\mathrm{ML}$ & $\mathrm{VH}$ & $\mathrm{MH}$ & $\mathrm{H}$ & $\mathrm{MH}$ & $\mathrm{EL}$ \\
\hline & $C_{2}$ & $\mathrm{~L}$ & $\mathrm{VL}$ & $\mathrm{VL}$ & $\mathrm{M}$ & $\mathrm{M}$ & $\mathrm{L}$ & $\mathrm{H}$ & $\mathrm{MH}$ & $\mathrm{M}$ & $\mathrm{VH}$ & $\mathrm{MH}$ & $\mathrm{M}$ & $\mathrm{ML}$ & VL \\
\hline & $C_{3}$ & $\mathrm{VL}$ & $\mathrm{L}$ & VL & $\mathrm{M}$ & $\mathrm{L}$ & ML & $\mathrm{MH}$ & $\mathrm{EH}$ & $\mathrm{VL}$ & $\mathrm{EH}$ & $\mathrm{H}$ & $\mathrm{MH}$ & $\mathrm{M}$ & $\mathrm{VL}$ \\
\hline \multirow{3}{*}{$E_{5}$} & $C_{1}$ & EL & $\mathrm{L}$ & EL & $\mathrm{M}$ & ML & $\mathrm{M}$ & $\mathrm{MH}$ & $\mathrm{VH}$ & ML & $\mathrm{H}$ & $\mathrm{H}$ & $\mathrm{VH}$ & $\mathrm{M}$ & EL \\
\hline & $C_{2}$ & VL & VL & $\mathrm{VL}$ & $\mathrm{MH}$ & $\mathrm{M}$ & ML & $\mathrm{M}$ & $\mathrm{MH}$ & $\mathrm{MH}$ & $\mathrm{H}$ & $\mathrm{MH}$ & $\mathrm{VH}$ & $\mathrm{L}$ & VL \\
\hline & $C_{3}$ & VL & ML & VL & ML & ML & ML & $\mathrm{M}$ & $\mathrm{VH}$ & $\mathrm{L}$ & $\mathrm{H}$ & $\mathrm{MH}$ & $\mathrm{H}$ & MH & $\mathrm{L}$ \\
\hline
\end{tabular}

TABLE 7: Intuitionistic fuzzy aggregation decision risk matrix of risk sources.

\begin{tabular}{lccr}
\hline No. & $C_{1}$ & $C_{2}$ & $C_{3}$ \\
\hline$H_{1}$ & $(0.0750,0.9116)$ & $(0.2328,0.7169)$ & $(0.0771,0.9085)$ \\
$H_{2}$ & $(0.2333,0.7164)$ & $(0.1309,0.8280)$ & $(0.1682,0.7917)$ \\
$H_{3}$ & $(0.1555,0.7991)$ & $(0.1270,0.8337)$ & $(0.1309,0.8280)$ \\
$H_{4}$ & $(0.4681,0.4806)$ & $(0.4162,0.5325)$ & $(0.4070,0.5425)$ \\
$H_{5}$ & $(0.3166,0.6333)$ & $(0.5410,0.4083)$ & $(0.2866,0.6632)$ \\
$H_{6}$ & $(0.4761,0.4723)$ & $(0.2825,0.6673)$ & $(0.4209,0.5287)$ \\
$H_{7}$ & $(0.6209,0.3267)$ & $(0.76350 .1837)$ & $(0.6642,0.2846)$ \\
$H_{8}$ & $(0.8710,0.1035)$ & $(0.7418,0.2041)$ & $(0.8358,0.1275)$ \\
$H_{9}$ & $(0.2774,0.6725)$ & $(0.5399,0.4083)$ & $(0.2065,0.7434)$ \\
$H_{10}$ & $(0.8426,0.1811)$ & $(0.7659,0.1811)$ & $(0.7900,0.1762)$ \\
$H_{11}$ & $(0.6889,0.2603)$ & $(0.6089,0.2449)$ & $(0.6889,0.2603)$ \\
$H_{12}$ & $(0.8169,0.1310)$ & $(0.2968,0.6531)$ & $(0.7091,0.2400)$ \\
$H_{13}$ & $(0.5587,0.6531)$ & $(0.0974,0.8778)$ & $(0.5587,0.3905)$ \\
$H_{14}$ & $(0.1719,0.7888)$ & $(0.1196,0.8503)$ \\
\hline
\end{tabular}

TABLE 8: Assessment summary of risk evaluation criteria.

\begin{tabular}{lccccccc}
\hline Criteria & $E_{1}$ & $E_{2}$ & $E_{3}$ & $E_{4}$ & $E_{5}$ & Aggregated IFNs & Score function value $S^{*}\left(C_{j}\right)$ \\
\hline$C_{1}$ & ES & VS & ES & ES & VS & $(0.8760,0.0703)$ & 0.9029 \\
$C_{2}$ & S & S & VS & VS & S & $(0.7279,0.2196)$ & 0.7542 \\
$C_{3}$ & $\mathrm{M}$ & $\mathrm{S}$ & $\mathrm{S}$ & $\mathrm{S}$ & $\mathrm{M}$ & $(0.6035,0.3457)$ & 0.6289 \\
\hline
\end{tabular}

we can see the superiority of this method compared with other methods.

Compared with the traditional TOPSIS method, $H_{4}$ and $H_{5}$ have the same risk ranking results, as well as $H_{6}$ and $H_{9}$, and the risk level cannot be distinguished. The specific reason is that fuzzy language is not used to characterize the value of linguistic variables, and the more risk sources, the same sorting results are likely to appear. Compared with the fuzzy TOPSIS method, the risk ranking result is different from the method proposed in this paper. The main reason for the difference is that the literature [33] uses fuzzy triangular numbers to represent fuzziness and uncertainty. In contrast, the intuitionistic fuzzy numbers used in this article can more accurately and genuinely reflect the fuzziness and uncertainty of expert evaluation information, avoid loss of information, and make the final risk level result more accurate. Compared with the fuzzy MOORA method, the risk ranking results are different. The main reasons are that the MOORA method does not consider the potential losses and gains values and the objective weight of the evaluation criteria is not considered, which results in the deviation of risk ranking orders. This is because the objective weight of risk assessment criteria is obtained by the method of normal distribution. Its essence is to give it a small objective weight for the risk evaluation criteria that are too large or too small in the subjective weight to minimize the impact of more extensive data on the final result.

5.4. Sensitivity Analysis. Sensitivity analysis is performed by changing the ratio of subjective weight to objective weight to test the stability and changes of the cruise ship construction 
TABLE 9: Subjective weight values obtained by the intuitionistic fuzzy SWARA method.

\begin{tabular}{lcccrr}
\hline Criteria & & $s_{j}$ & $k_{j}$ & $q_{j}$ & $\lambda_{j}$ \\
\hline$C_{1}$ & 0.9029 & - & 1 & 1 & 0.3782 \\
$C_{2}$ & 0.7542 & 0.1487 & 1.1487 & 0.8705 & 0.3292 \\
$C_{3}$ & 0.6289 & 0.1253 & 1.1253 & 0.7736 & 0.2926 \\
\hline
\end{tabular}

TABLE 10: Final results and ranking of risk sources $(\phi=0.6)$.

\begin{tabular}{|c|c|c|c|c|c|c|c|c|c|c|}
\hline \multirow{2}{*}{ No. } & \multicolumn{2}{|c|}{$C_{1}$} & \multicolumn{2}{|c|}{$C_{2}$} & \multicolumn{2}{|c|}{$C_{3}$} & \multirow{2}{*}{$D^{+}$} & \multirow{2}{*}{$D^{-}$} & \multirow{2}{*}{$G$} & \multirow{2}{*}{ Sor } \\
\hline & $F_{1}^{+}$ & $F_{1}^{-}$ & $F_{2}^{+}$ & $F_{2}^{-}$ & $F_{3}^{+}$ & $F_{3}^{-}$ & & & & \\
\hline$H_{1}$ & 0.0817 & 0.9183 & 0.2579 & 0.7421 & 0.0843 & 0.9157 & 0.1749 & 0.8449 & 0.8285 & 12 \\
\hline $\mathrm{H}_{2}$ & 0.2585 & 0.7415 & 0.1515 & 0.8485 & 0.1882 & 0.8118 & 0.2002 & 0.8001 & 0.7998 & 11 \\
\hline $\mathrm{H}_{3}$ & 0.1782 & 0.8218 & 0.1467 & 0.8533 & 0.1515 & 0.8485 & 0.1579 & 0.8367 & 0.8412 & 13 \\
\hline $\mathrm{H}_{4}$ & 0.4937 & 0.5063 & 0.4419 & 0.5581 & 0.4323 & 0.5677 & 0.4544 & 0.4977 & 0.5228 & 7 \\
\hline $\mathrm{H}_{5}$ & 0.3417 & 0.6583 & 0.5664 & 0.4336 & 0.3117 & 0.6883 & 0.4382 & 0.5827 & 0.5708 & 8 \\
\hline$H_{6}$ & 0.5019 & 0.4981 & 0.3076 & 0.6924 & 0.4461 & 0.5539 & 0.4141 & 0.5944 & 0.5894 & 9 \\
\hline $\mathrm{H}_{7}$ & 0.6471 & 0.3529 & 0.7899 & 0.2101 & 0.6898 & 0.3102 & 0.7149 & 0.2883 & 0.2874 & 5 \\
\hline$H_{8}$ & 0.8837 & 0.1163 & 0.7689 & 0.2311 & 0.8542 & 0.1458 & 0.8256 & 0.1771 & 0.1766 & 1 \\
\hline$H_{9}$ & 0.3024 & 0.6976 & 0.5658 & 0.4342 & 0.2316 & 0.7684 & 0.4147 & 0.6223 & 0.6001 & 10 \\
\hline$H_{10}$ & 0.8567 & 0.1433 & 0.7924 & 0.2076 & 0.8069 & 0.1931 & 0.8129 & 0.1837 & 0.1843 & 2 \\
\hline$H_{11}$ & 0.7143 & 0.2857 & 0.7296 & 0.2704 & 0.7143 & 0.2857 & 0.7162 & 0.2779 & 0.2795 & 4 \\
\hline$H_{12}$ & 0.8429 & 0.1571 & 0.6350 & 0.3650 & 0.7345 & 0.2655 & 0.7303 & 0.2825 & 0.2789 & 3 \\
\hline$H_{13}$ & 0.5841 & 0.4159 & 0.3218 & 0.6782 & 0.5841 & 0.4159 & 0.4909 & 0.5347 & 0.5214 & 6 \\
\hline$H_{14}$ & 0.1916 & 0.8084 & 0.1098 & 0.8902 & 0.1347 & 0.8653 & 0.1465 & 0.8523 & 0.8534 & 14 \\
\hline
\end{tabular}

TABLE 11: Ranking of risk sources by different methods.

\begin{tabular}{lcccc}
\hline No. & $\begin{array}{c}\text { Proposed } \\
\text { method }\end{array}$ & TOPSIS & $\begin{array}{c}\text { Fuzzy } \\
\text { TOPSIS }\end{array}$ & $\begin{array}{c}\text { Fuzzy } \\
\text { MOORA }\end{array}$ \\
\hline$H_{1}$ & 12 & 12 & 12 & 14 \\
$H_{2}$ & 11 & 11 & 11 & 12 \\
$H_{3}$ & 13 & 14 & 14 & 11 \\
$H_{4}$ & 7 & 9 & 6 & 8 \\
$H_{5}$ & 8 & 9 & 9 & 7 \\
$H_{6}$ & 9 & 6 & 8 & 10 \\
$H_{7}$ & 5 & 3 & 5 & 4 \\
$H_{8}$ & 1 & 1 & 1 & 3 \\
$H_{9}$ & 10 & 6 & 10 & 6 \\
$H_{10}$ & 2 & 2 & 2 & 1 \\
$H_{11}$ & 4 & 5 & 4 & 2 \\
$H_{12}$ & 3 & 3 & 3 & 5 \\
$H_{13}$ & 6 & 10 & 7 & 9 \\
$H_{14}$ & 14 & 13 & 13 & 13 \\
\hline
\end{tabular}

occupational health and safety management risk assessment model. By changing the parameter $\phi$ value, seven kinds of risk source rankings under different subjective and objective weights are obtained. The corresponding risk source rankings are shown in Table 12. According to Table 12, when the value $\phi$ changes, it will inevitably affect the final ranking. When the value $\phi$ gradually changes from 0 to 1 , there are a total of nine risk sources (64\%) with different risk priority rankings in seven cases. In this sense, the ranking of risk sources differs significantly under different $\phi$ values. The selection of the $\phi$ value depends on the decision-makers, which is determined according to the actual situation of the shipbuilding enterprise, to weigh the impact of subjective weight and objective weight on the ranking of risk sources. If the decision-makers are highly confident in the relevant data
TABLE 12: Sensitivity analysis of $\phi$ value.

\begin{tabular}{cccccccc}
\hline No. & \multicolumn{7}{c}{ Sort } \\
& $\phi=0.0$ & $\phi=0.2$ & $\phi=0.4$ & $\phi=0.5$ & $\phi=0.6$ & $\phi=0.8$ & $\phi=1.0$ \\
\hline$H_{1}$ & 12 & 12 & 12 & 12 & 12 & 12 & 13 \\
$H_{2}$ & 11 & 11 & 11 & 11 & 11 & 11 & 11 \\
$H_{3}$ & 13 & 13 & 13 & 13 & 13 & 13 & 12 \\
$H_{4}$ & 8 & 7 & 7 & 7 & 7 & 7 & 7 \\
$H_{5}$ & 6 & 8 & 8 & 8 & 8 & 8 & 9 \\
$H_{6}$ & 10 & 10 & 10 & 9 & 9 & 9 & 8 \\
$H_{7}$ & 3 & 3 & 4 & 5 & 5 & 5 & 5 \\
$H_{8}$ & 1 & 1 & 1 & 1 & 1 & 1 & 1 \\
$H_{9}$ & 9 & 9 & 9 & 10 & 10 & 10 & 10 \\
$H_{10}$ & 2 & 2 & 2 & 2 & 2 & 2 & 2 \\
$H_{11}$ & 4 & 4 & 3 & 3 & 4 & 4 & 4 \\
$H_{12}$ & 5 & 5 & 5 & 4 & 3 & 3 & 3 \\
$H_{13}$ & 7 & 6 & 6 & 6 & 6 & 6 & 6 \\
$H_{14}$ & 14 & 14 & 14 & 14 & 14 & 14 & 14 \\
\hline
\end{tabular}

obtained, a more significant value $\phi$ can be used. Otherwise, a smaller value can be used. When there are no data to learn from, the general value $\phi$ can be 0.6 or 0.5 . This method is applied to the risk assessment of occupational health and safety in cruise ship construction for the first time in this paper. There are no historical data to learn from, so the value in this paper is 0.6 .

\section{Conclusion}

Because of the complexity, long period, and difficulty of cruise ship construction and the high occupational health and safety risk coefficient caused by it, an improved intuitionistic fuzzy TOPSIS decision model for cruise ship 
construction risk assessment is proposed to overcome the defects of the traditional TOPSIS decision model. The improved intuitionistic fuzzy TOPSIS decision model has the following advantages:

(1) The intuitionistic fuzzy numbers are used to represent fuzziness and uncertainty, and objective weight is introduced. The intuitionistic fuzzy numbers can express the decision-maker's preference for the membership degree, nonmembership degree, and hesitation. It can more comprehensively describe the fuzziness and uncertainty of occupational health and safety risk sources in cruise ship construction. The evaluation of risk sources is based on the intuitionistic fuzzy number to express preference degree, and the intuitionistic fuzzy weighted arithmetic average operator is used for aggregation. When determining the relative importance weight of risk assessment criteria, the subjective weight of the SWARA method and the objective weight based on normal distribution are introduced. The risk assessment results are more accurate and closer to the actual situation.

(2) The results show that in the cruise ship construction process, the three lowest risk sources are employees with certificates $\left(H_{14}\right)$, insufficient safety investment $\left(H_{3}\right)$, and equipment failure $\left(H_{1}\right)$. This shows that shipbuilding enterprises attach great importance to cruise ship construction, speed up equipment renewal to ensure integrity, increase safety capital investment to ensure that everyone knows the importance of safety, and ensure that employees work with certificates. Insufficient employee safety training $\left(H_{8}\right)$, unsafe behavior of employees $\left(H_{10}\right)$, and noise hazards $\left(H_{12}\right)$ were the three highest risk sources. It shows that cruise ship construction has its uniqueness and requires high-quality employees. For example, many suppliers are from abroad, and the material names are in English. If the employees of Chinese shipbuilding enterprises cannot correctly identify the English material names, it is easy to affect the work efficiency and cause some harm. Therefore, we must take corresponding risk prevention measures because of the high-risk items of occupational health and safety in cruise ship construction, that is, we should continue to strengthen the training of management personnel and front-line staff, especially the training of cruise ship-related knowledge and take relevant measures to control noise hazards and contact with toxic and harmful materials.

(3) The occupational health and safety risk assessment of cruise ship construction is a dynamic and continuous improvement process. The source of risk can change with the passage of construction time and is not static. Due to external and internal incidents in the construction of cruise ships, the monitoring and review of occupational health and safety risks have been ongoing. Some new risk sources may appear, and some risk sources will disappear. Therefore, shipbuilding enterprises should often organize occupational health and safety experts, senior managers, or team leaders to carry out risk monitoring and control. Because of the fuzziness and uncertainty of occupational health and safety risk assessment, decision-makers express their preference based on the intuitionistic fuzzy number and weigh the subjective weight and objective weight of assessment criteria. The improved intuitionistic fuzzy TOPSIS decision model proposed in this paper can provide crucial theoretical reference for risk prevention and control of occupational health and safety in cruise ship construction.

(4) As the construction of cruise ships is a complex system project with multiple types of work, multiple disciplines, long duration, and continuous operation, many factors affect occupational health and safety. Therefore, the content and knowledge involved in the occupational health and safety risk assessment of cruise ship construction should be wider. The following aspects can be studied and improved in the next step: first, the evaluation criteria need further study. Second, the ratio of the subjective weight and the objective weight of the evaluation criteria must be set. Third, the evaluation decision model constructed in this article is based on questionnaire data. The workload of data processing and analysis is relatively large, and how to effectively process the data needs further research.

\section{Data Availability}

The data used to support the findings of this study are included in the article.

\section{Conflicts of Interest}

The authors declare that there are no conflicts of interest regarding the publication of this article.

\section{Acknowledgments}

This research was supported by the National Natural Science Foundation of China (51809203, 51709214, and 51779200).

\section{References}

[1] E. Ilbahar, A. Karaşan, A. An, S. Cebi, and C. Kahraman, “A novel approach to risk assessment for occupational health and safety using Pythagorean fuzzy AHP \& fuzzy inference system," Safety Science, vol. 103, no. 1, pp. 124-136, 2018.

[2] R. Dabbagh and S. Yousefi, "A hybrid decision-making approach based on FCM and MOORA for occupational health and safety risk analysis," Journal of Safety Research, vol. 71, pp. 111-123, 2019.

[3] L. A. Zadeh, "Fuzzy sets," Information and Control, vol. 8, no. 3, pp. 338-353, 1965.

[4] K. T. Atanassov, "Intuitionistic fuzzy sets," Fuzzy Sets and Systems, vol. 20, no. 6, pp. 87-96, 1986.

[5] E. K. Zavadskas, A. Mardani, and Z. Turskis, "Development of TOPSIS method to solve complicated decision-making 
problems-an overview on developments from 2000 to 2015," International Journal of Information Technology and Decision Making, vol. 15, no. 3, pp. 645-682, 2016.

[6] R. Szpotowicz and T. Csaba, "Revision of sustainable road rating systems: selection of the best suited system for Hungarian road construction using TOPSIS method," Sustainability, vol. 12, no. 21, Article ID 8884, 2020.

[7] Z. Wu, S. Huang, and W. Hu, "Research on the selection of green building projects based on combination weightingimproved TOPSIS method," World Scientific Research Journal, vol. 6, no. 10, pp. 93-105, 2020.

[8] C. Yu, Z. Zou, Y. Shao, and F. Zhang, "An integrated supplier selection approach incorporating decision maker's risk attitude using ANN, AHP and TOPSIS methods," Kybernetes, vol. 49, no. 9, pp. 2263-2284, 2020.

[9] A. Mohamadghasemi, A. Hadi-Vencheh, and F. Hosseinzadeh Lotfi, "The multiobjective stochastic CRITIC-TOPSIS approach for solving the shipboard crane selection problem," International Journal of Intelligent Systems, vol. 35, no. 10, pp. 1570-1598, 2020.

[10] T.-M. Choi, C.-H. Chiu, and H.-K. Chan, "Risk management of logistics systems," Transportation Research Part E: Logistics and Transportation Review, vol. 90, pp. 1-6, 2016.

[11] V. Stefanovića, S. Uroševićb, and I. Mladenović-Ranisavljević, "Multi-criteria ranking of workplaces from the aspect of risk assessment in the production processes in which women are employed," Safety Science, vol. 116, pp. 116-126, 2019.

[12] H. Lingard, "The effect of first aid training on Australian construction workers' occupational health and safety motivation and risk control behavior," Journal of Safety Research, vol. 33, no. 2, pp. 209-230, 2002.

[13] D. Charles, Occupational Health and Safety Management: A Practical Approach, CRC Press, Boca Raton, FL, USA, 3rd edition, 2018.

[14] T. L. Sellnow, M. W. Seeger, and R. R. Ulmer, Effective Risk Communication, Springer, New York, NY, USA, 2009.

[15] S. Loranger and J. Zayed, "Environmental and occupational exposure to manganese: a multimedia assessment," International Archives of Occupational and Environmental Health, vol. 67, no. 2, pp. 101-110, 1995.

[16] Z. Ismail, S. Doostdar, and Z. Harun, "Factors influencing the implementation of a safety management system for construction sites," Safety Science, vol. 50, no. 3, pp. 418-423, 2012.

[17] Z. Xiang, J. Yang, M. H. Naseem, Z. Xiang, and X. Liang, "Supplier selection of shipbuilding enterprises based on intuitionistic fuzzy multicriteria decision," Mathematical Problems in Engineering, vol. 2021, Article ID 1775053, 11 pages, 2021.

[18] P. H. Nguyen and M. Boninsegni, "Superfluid transition and specific heat of the 2D $x-y$ model: Monte Carlo simulation," Applied Sciences, vol. 11, no. 11, p. 4931, 2021.

[19] S. Wang, Y. Zhang, C. Zhang, and M. Yang, "Improved artificial neural network method for predicting photovoltaic output performance," Global Energy Interconnection, vol. 3, no. 6, pp. 553-561, 2020.

[20] F. Yu, Y. Wu, X. M. Shao, and J. C. Guo, "Fuzzy comprehension evaluation of sunny sports activity using entropy weight," Applied Mechanics and Materials, vol. 539, no. 539, pp. 908-910, 2014.

[21] M. Hodkiewicz, J. W. Klüwer, C. Woods, T. Smoker, and E. Low, "An ontology for reasoning over engineering textual data stored in FMEA spreadsheet tables," Computers in Industry, vol. 131, no. 1, Article ID 103496, 2021.
[22] L. Liu, Y. Zhao, and Y. Huang, "Evaluation of LEC and VGFInAs substrates through surface defect characterization and epitaxy growth," Materials Science in Semiconductor Processing, vol. 125, no. 8, Article ID 105624, 2021.

[23] H. Garg, U. Kifayat, M. Tahir, N. Hassan, and N. Jan, “Tspherical fuzzy power aggregation operators and their applications in multi-attribute decision making," Journal of ambient intelligence and humanized computing, vol. 2021, pp. 1-14, 2021.

[24] M. Goyal, D. Yadav, and A. Tripathi, "Intuitionistic fuzzy genetic weighted averaging operator and its application for multiple attribute decision making in E-learning," Indian Journal of Science and Technology, vol. 9, no. 1, pp. 1-15, 2016.

[25] Z. Xu, "Methods for aggregating interval-valued intuitionistic fuzzy information and their application to decision making," Control and Decision, vol. 22, no. 2, pp. 215-219, 2007.

[26] S.-P. Wan, S.-P. Wan, and X.-L. Xie, "A selection method based on MAGDM with interval-valued intuitionistic fuzzy sets," Mathematical Problems in Engineering Theory Methods \& Applications, vol. 2015, Article ID 791204, 13 pages, 2015.

[27] Z. Xu, "A deviation-based approach to intuitionistic fuzzy multiple attribute group decision making," Group Decision and Negotiation, vol. 19, no. 1, pp. 57-76, 2010.

[28] H.-C. Liu, L. Liu, and P. Li, "Failure mode and effects analysis using intuitionistic fuzzy hybrid weighted Euclidean distance operator," International Journal of Systems Science, vol. 45, no. 10, pp. 2012-2030, 2014.

[29] Z. Xu, "An overview of methods for determining OWA weights," International Journal of Intelligent Systems, vol. 20, no. 8, pp. 843-865, 2005.

[30] V. Ker suliene, E. K. Zavadskas, and Z. Turskis, "Selection of rational dispute resolution method by applying new step-wise weight assessment ratio analysis (SWARA)," Journal of Business Economics and Management, vol. 11, no. 2, pp. $243-258,2010$.

[31] N. Zarbakhshnia, H. Soleimani, and H. Ghaderi, "Sustainable third-party reverse logistics provider evaluation and selection using fuzzy SWARA and developed fuzzy COPRAS in the presence of risk criteria," Applied Soft Computing, vol. 65, no. 1, pp. 307-319, 2018.

[32] Z. S. Xu and Q. L. Da, "The uncertain OWA operator," International Journal of Intelligent Systems, vol. 17, no. 6, pp. 569-575, 2002.

[33] M. Gul and M. F. Ak, "A comparative outline for quantifying risk ratings in occupational health and safety risk assessment," Journal of Cleaner Production, vol. 196, pp. 653-664, 2018.

[34] B. Turanoglu, G. Akkaya, and O. Sinan, "An integrated fuzzy AHP and fuzzy MOORA approach to the problem of industrial engineering sector choosing," Expert Systems with Applications, vol. 42, no. 24, pp. 9565-9573, 2015. 